\title{
O MATERNO E A DELINQÜÊNCIA
}

Michèle Benhaim

Psicanalista, professora de Psicopatologia Clínica no Laboratoire de Psicopatologia Clínica e Psicanálise da Université de Provence, Centre Saint-Charles.

Tradução Jean-Jacques Rassial

RESUMO: O período adolescente pode se transformar em desamparo, e a desajuda em errância subjetiva e social. A função materna foi operante? Nesse tempo primeiro, inscrever-se-ia a falha que o ato delinqüente virá preencher. A problemática delinqüente repousaria não sobre uma intolerável desilusão, mas sobre uma falta de ilusão. O desamparo infantil pode se desdobrar em desespero juvenil, no qual nada pode intervir como mediação.

Palavras-chave: Adolescência, delinqüência, mãe, sintoma.

ABSTRACT: Motherhood and delinquency. The period teenager can pour in the transformation of the distress, the désaide, in wander, subjective and social. Has the maternal function been operative? In this primary time the fault would fit which the delinquent act will come to fill. The delinquent problems would rest not on an intolerable disillusion but on a defect of illusion. The infantile distress can rock in youthful despair that nothing comes to mediate.

Keywords: Adolescence, delinquency, mother, symptom.

“oui j’ai les yeux fermés à votre lumière, je suis une bête, un nègre. Je ne comprends pas les lois, je n'ai pas le sens moral, je suis une brute, vous vous trompez!"

(Arthur Rimbaud)

\section{INTRODUÇÃO}

Minha obra intitulada La folie des mères [A loucura das mães], publicada em 1991, trazia à luz o que eu então identificava como um fantasma que atravessa cada mulher que se torna mãe e que a inscreveria na "loucura”. A loucura era considerada aí não no sentido de uma estrutura psicótica da personalidade, mas talvez mais no sentido dado por Hipócrates (HIPOCRATE, 2000) à loucura das parturientes, e sobretudo como passagem inevitavelmente imbricada no processo de maternidade. Poder- 
se-ia acrescentar um paralelo entre essa "passagem materna” e a "passagem adolescente" - a primeira induzida pelo parto, a segunda pela puberdade. Essas duas passagens, por fim, obrigatórias para o corpo em questão por um evento incontrolável, para-além do sujeito, sutil travessia do real de que se sai inevitavelmente transformado, louca ou púbere, mãe ou adolescente. Hoje podemos até mesmo concluir que do primeiro "tempo de recapitulação" da infância, que é a passagem adolescente, decorrerão certos aspectos deste "questionamento importante da idade adulta" que é o acesso à maternidade.

O que sustenta então a estrutura do desejo, 're-posicionado' tanto num caso quanto em outro, no melhor dos casos, na mãe sob a forma de um fantasma mais ou menos consciente, no adolescente sob a forma de sintomas de tipo fóbico em geral, com o benefício, aqui e ali, de recuperar o sentido simbólicoimaginário que permita à mãe ocupar sua função, ao adolescente crescer, com altos e baixos, tanto para um quanto para outro; no pior dos casos, através de uma passagem materna ao ato e por uma espécie de equivalente adolescente, que seria a conduta dita "delinqüente".

\section{O MATERNO}

O processo de maternidade poderia definir-se aqui como uma "passagem": o momento em que uma mulher tem acesso à maternidade no real, nesse tempo de ruptura no corpo que marca o parto, que é acompanhado de um tempo de mudança imaginário, fantasmático, de ruptura psíquica em eco. Tornar-se mãe equivale a tornar-se culpada por inscrever a criança na ordem da mortalidade, e, portanto e conseqüentemente, culpada por tudo o que lhe possa ocorrer.

O laço entre o materno e a culpa reflete desde já os determinantes desse terrível poder que consiste em dar a vida, e portanto a morte, e do todo-poder materno que daí decorre necessariamente, mas que vem se declinar de modo mais ou menos patológico segundo os sujeitos e sua inscrição em sua própria história infantil, isto é, em sua própria relação com o enigma do desejo de suas mães.

\section{ADOLESCÊNCIA}

A adolescência parece ser esse período situado no cruzamento entre o real e a realidade, porque é uma passagem em que a interação entre a realidade e a construção psíquica é estreita. Com efeito, é o tempo de reorganização do sintoma, comprometido entre o desejo e a dita realidade do fantasma, matriz que auxilia a suportar o que esta realidade contém de horror, isto é, do que se fará, de modo mais ou menos fixo nesse momento, laço social para um sujeito.

De que modo o adolescente vai lidar imaginariamente em sua elaboração de traços identificatórios que o representam no mundo e de movimentos que 
o permitam regular suas relações com o mundo? Terá ele sempre todos os elementos necessários à construção de seu sintoma?

No momento dessa passagem, um sintoma deve sustentar o desejo do sujeito tornado adolescente. O que coloca a questão de saber o que é feito do objeto de amor da infância, a mãe.

Mas outras questões também estão na ordem do dia: O que foi feito da suposta potência fálica do pai? De que modo o drama da castração (drama que repousa sobre o fato de que ninguém detém o falo), sobrevindo aqui em toda sua grandeza, poderia não se orientar para a tragédia? A adolescência, como a maternidade, convoca a uma renúncia. A psicopatologia adolescente, em sua vertente de repetidas passagens ao ato, de que testemunham "a delinqüência” e a psicopatologia materna, cujos aspectos são amplamente descritos em $A$ loucura das mães, parecem estar no centro desses determinantes de uma impossível renúncia. Renúncia a quê? A quem?

\section{"DELINQÜÊNCIA"}

O adolescente "delinqüente" é uma figura de discurso, mais do que uma construção psicopatológica. Ele parece implantar, do fundo de seu desamparo/errância, a busca desesperada e vã, portanto repetitiva, de alcançar esse objeto ao qual sua estruturação psíquica não lhe permite renunciar, a não ser talvez ao preço da loucura ou da morte.

A castração "é culpa dos pais”. Além deles, não haveria mais ninguém? O céu estaria assim vazio... Isto marcará os perigos eventuais da necessária rearticulação simbólica requeridos pela passagem e pela renúncia adolescentes. Esses perigos podem então traduzir-se numa psicopatologia violenta para todos e em primeiro lugar para o próprio adolescente que, dizendo-o ou mostrandoo, não domina mais nada de suas pulsões, na medida que falta o dedo decisivo de Deus.

Uma significativa falta definitivamente no Outro e este "mau caráter" não o estrutura: para ele isto é insuportável.

Apenas diante do vazio o adolescente "delinqüente" não parece dispor da ilusão fundadora necessária à construção de um narcisismo também fundador. A ilusão é a de ter sido preenchido por sua mãe e de preenchê-la. Este defeito de ilusão condiciona de algum modo e conseqüentemente a ausência de base de sustentação do processo desilusório, tempo da frustração também necessário para desfazer-se do domínio mortífero e que teria compensado um espaço transicional em que um objeto do mesmo nome teria sido eleito, amenizando a perda e a depressão que a acompanha de modo inevitável.

Minha hipótese aqui é a de que, se o período adolescente pode se resolver nesta descoberta suportável para o sujeito, ele pode também orientar-se para a 
transformação do desamparo, a desajuda ${ }^{1}$ em errância, que deve ser compreendida aqui em sua dupla dimensão: por não se enganar com o significante, o sujeito erra psiquicamente e, se esse não-assujeitamento à língua dá lugar à passagem ao ato, o sujeito erra socialmente.

Esta errância subjetiva se caracteriza por uma espécie de imaturidade, de desequilíbrio, de impulsividade e, sobretudo, pelo fato de os eventos do tipo ‘passagens ao ato' não fazerem sentido e só se inscreverem como momentos que pontuam o tempo e obedecem a uma lógica particular de ausência de engajamento, de implicação do sujeito. Errância ou des-errância, a existência é sem limites, sem enquadre, sem fundo, excessiva. Lembremo-nos de que Freud colocava um princípio segundo o qual o que é excesso em um dos opostos, é carência em outro. Ou ainda, o que faz excesso participa da inibição de outras capacidades subjetivas. E também, em que estado-limite (RASSIAL, 1999) se posiciona irredutivelmente o sujeito?

Como qualificar essas posições subjetivas que agem destruindo deliberadamente tudo, inclusive as tentativas de amor de que eles podem ser objeto, contendo, assim, de fato, uma espécie de impossibilidade em pensar?

Quanto à errância geográfica, pode-se constatar que uma espécie de busca os leva sem cessar de lugar em lugar numa espécie de falta de historicidade.

Para prosseguir nesta tentativa de articulação do materno com os determinantes da adolescência e, circundando o aspecto psicopatológico que nos interessa - os determinantes da adolescência delinqüente - evocarei de modo breve a questão colocada ao pai na operação adolescente quanto ao estatuto do falo e a seu posicionamento em relação a ele, ser de carne e osso, pai real, sempre e para sempre agente castrador quanto a esse significante: em outras palavras, como ele, homem, lida com a castração?

Não podemos deixar, aqui, de associar esta questão ao devir da figura materna nesta mesma operação adolescente.

Esta questão, e é o que mostra a clínica cotidiana dos adolescentes vítimas de condutas ditas delinqüentes, refere-se por fim à legitimidade dessas novas figuras do Outro: de que lugar falam comigo? Com que legitimidade?

A questão, em resposta a "houve pai?”, “a função materna foi operante?”, encontra resposta na adolescência. Mãe no sentido em que consideramos sua função como estrutural. Existem elementos do psiquismo que somente a mãe pode trazer: é o que pode ser analisado na questão relativa à psicopatologia da delinqüência.

Aquela que vem em socorro do bebê em desamparo é a "mãe simbólica”, a que dá a primeira mamada, o objeto real, o leite: nesse primeiro tempo é que

\footnotetext{
${ }^{1}$ Em francês, désaide (N. da T.).
} 
se inscreveria a falha que o ato delinqüente viria a preencher. A falha seria essa palavra que não viria a tempo para dizer, meio dita, a Coisa (FREUD, 1895/1973), tendo a mãe se ausentado muito cedo, não tendo preenchido a criança no tempo furtivo, mas vital, para que se instale a ilusão, base de sustentação de sua capacidade vindoura de criar. A mãe, de algum modo desiludindo-o sem suporte, não o permitiu habitar um lugar, o da ilusão, o do objeto achado-criado, que ele então teria podido abandonar. Suportar a perda repousa sobre o recalque originário. É preciso que algo esteja submetido ao recalque: se o psicótico continua a ser confrontado ao horror (da Coisa) nesse lugar para onde ela deveria ter fugido para sempre, poderíamos, talvez, colocar a hipótese de que o sujeito vítima de uma relação delinqüente com o mundo nada tem a dissimular: o que faria falta da falta para o psicótico, que não cessará de preenchê-lo através do real que faz retorno na construção delirante ou na alucinação imaginária, e vazio sem fundo para o adolescente, que não teria outro recurso a não ser agarrar-se às paredes da passagem ao ato para não desaparecer.

\section{A PROBLEMÁTICA DELINQÜENTE REPOUSARIA NÃO SOBRE UMA INTOLERÁVEL DESILUSÃO, MAS SOBRE UMA FALTA DE ILUSÃO}

Para além do objeto real, encontra-se o “objeto” imaginário e simbólico do amor: poder-se-ia levantar a hipótese de que o adolescente vítima das condutas delinqüentes nunca tenha suplantado o objeto imaginário e simbólico do amor, por ter sido inicialmente situado na ilusão da completude compartilhada?

São esses os elementos dos quais se pode dizer que vêm exclusivamente da mãe e dão à sua função uma dimensão estrutural: a partir de seu imaginário a mãe dá à criança o sentido do real graças ao simbólico — nesse ponto se articula o que fará sintoma para o adolescente. Este último será testemunha da tripla capacidade em efetuar essa passagem sem muitos percalços: a criação, a re-criação, a recreação.

Criação no sentido de lidar com uma nova realidade, re-criação no sentido em que, dialeticamente, mãe e adolescente devem modificar suas respectivas posições quanto ao desejo, recreação enfim no sentido em que os múltiplos lutos que o adolescente deve fazer exigem uma energia permanente que requer às vezes a abstração do trabalho psíquico a ser realizado. É o espaço da ação, em lugar do pensamento, como evitamento da exaustão.

Durante um tempo, os adolescentes delinqüentes vão melhor do que os adolescentes deprimidos. Este é um dos pontos desenvolvidos por Jean-Jacques Rassial em seus trabalhos sobre o tema da adolescência.

Talvez porque se apresente ainda para eles a questão, e certamente de modo violento, da necessidade absoluta de ter referências em relação à filiação, à lei, 
ao pai, mais do que no todo-poder exclusivo da figura de um Outro identificado a um "educador" que proferiria uma "lei" incompreensível que faria referência à obrigação, mais do que à "paternidade".

$\mathrm{O}$ ato delinqüente poderia vir como uma tentativa radical de realizar a separação e/ou a saída do domínio, num movimento não mais marcado pela agressividade linguageira própria da crise adolescente, mas por uma violência física que, pelo menos, mantém o outro à distância. O que protege do Outro é o amor, e esta dimensão simbólico-imaginária falha. A única solução é não encontrá-lo, e até mesmo abatê-lo. A violência, nesse lugar, exprime-se no adolescente com freqüência, como vindo de um paradoxo no qual é possível inscrever-se. Essas passagens ao ato muitas vezes conduzem ao sentimento de ameaça, podendo até mesmo destruir o laço, mas parecem também ser a última tentativa de resolução da angústia ligada a este impossível do laço.

Finalmente, poderíamos dizer que o espaço em que a mãe falha em acompanhar a passagem do "infantil ao juvenil" e que hoje se traduz bastante nessas formas psicopatológicas que consistem em atuações, reatualiza esse tempo arcaico em que ela deveria acompanhar a dolorosa passagem do gozo ao desejo, com a nuance de que esta passagem exigiria que o bebê tivesse sido primeiramente "um puro ser de gozo".

Para se construir, e porque se trata de uma verdadeira construção, a ambivalência (materna) não poderia fazer economia nem do amor total nem do todo-ódio, pelo menos nesse movimento de balanço furtivo, quase mítico, em que da necessidade se separa o desejo e se elabora a demanda. Poderíamos supor que aqui o impasse seja feito sobre o amor (materno) primordial?

Se definirmos a mãe real como sendo a mulher na mãe, podemos supor que o trabalho necessário à adolescência irá requerer um novo confronto com essa figura e irá se apoiar nos efeitos da primeira confrontação, nesse tempo arcaico acima evocado. Parece que uma das dimensões da conduta delinqüente na adolescência, como meio constantemente exclusivo de "dizer", vem desse reconhecimento impossível da mulher na mãe, reconhecimento esse podendo originar-se somente no conhecimento, insuportável porque prematuro, contrariamente à psicose na qual o conhecimento seria pura e simplesmente inexistente. O impossível reconhecimento implica a impossível renúncia...

É a pacificação das figuras maternas, real, simbólica, imaginária, que sustenta a dimensão simbólica do pai, isto é, a regulação do desejo pela função fálica e não pela derivação numa pura lógica de gozo.

Se a maternidade engaja o sujeito a ter que lidar com seu triplo lugar de filha, de mulher e de mãe, a adolescência é o tempo em que essa tripla relação fica submetida ao questionamento a partir de um remanejamento identificatório próprio a essa passagem. 
O questionamento dirá respeito ao pai: se o próprio pai está submetido à falta e não detém o falo, mais do que qualquer outro, como ele faz para satisfazer a mãe e fazê-la mulher? O que é um homem? O pai real.

O adolescente faz essas duas perguntas ao Outro, e se este último "não cede a seu desejo", então ele pode crescer...

Sem isso, no melhor dos casos, ele vai "parecer grande", e no pior, orientarse-á para a figura do herói cuja mitologia nos indica que, às vezes, nada virá justificar sua monstruosa atitude pura e simplesmente injustificável.

O desdobramento do desamparo em errância também poderia ser o caso para numerosos adolescentes, para os quais na mudança do desamparo infantil para o desespero juvenil não houve qualquer mediação: o sofrimento, eles o amam e o detestam, eles manifestam seu desagrado, são deliberadamente impertinentes, tornam-se insuportáveis porque tudo lhes é insuportável e eles têm horror a tudo.

A angústia é inconfessável porque é não confessa, e o drama acaba por só poder se desenrolar, às vezes, nos confins extremos da violência: o ato violento surge aqui como uma tentativa paradoxal de restabelecer, numa forma de urgência, um laço posto à prova e só podendo ser apreendido através do outro.

Para concluir, insistamos sobre a necessidade de um momento de "ilusão" para a mãe, em resposta a esta área de ilusão indispensável ao bebê, segundo Winnicott, para atravessar os tempos de dependência absoluta e relativa, e ter acesso à independência. Necessidade semelhante na construção do materno: atravessar a ilusão de não ser castrada para que a criança seja esse "puro ser de gozo", para que haja para essa última um lugar a ser abandonado, e para que haja um lugar para o pai: o de ser o agente da castração da mãe.

Sem isso, o recém-nascido se confrontará com uma forma de melancolia materna, preso no desespero materno de uma perda muito brutal e muito radical. E esta posição melancoliforme se combina com a "melancolização do laço social" (conceito de Olivier Douville) e, para os adolescentes enredados nos processos que acabamos de descrever, essa falha da constituição da(s) ilusão(ões) conduz a formas de inacabamento.

A falha da mãe, acrescida aqui pelo fracasso social, inscreve-se imediatamente como $S(\mathbb{A})$. Ora, é castrando a mãe que o pai real se torna guardião da função simbólica.

\section{AS DESLIGAÇÕES SÃO PERIGOSAS: ELAS LEVAM AO DESESPERO...}

O desespero, no centro da inumana condição moderna, é inconsolável. É disso que parece testemunhar, em seu ato, este "herói” trágico atual, este mau-caráter que é o adolescente delinqüente. 


\section{REFERÊNCIAS}

FREUD, S. (1895/1973) "Esquisse pour une psychologie scientifique”, in La naissance de la psychanalyse. Presses Universitaires de France. (collection Psychanalyse).

HIPPOCRATE. (2000) Maximes et pensées. Paris: André Silvaire.

RASSIAL J.-J. (1999) Le sujet en état limite. Paris: Denoel. 